\title{
Maternal mortality review by three delay model: a retrospective study from a tertiary care hospital of Chhattisgarh
}

\author{
Sangeeta R. Jogi, Anju R. Ekka* \\ Department of Obstetrics and Gynaecology, Chhattisgarh Institute of Medical Sciences, Bilaspur, Chhattisgarh, India \\ Received: 28 October 2020 \\ Accepted: 05 December 2020 \\ *Correspondence: \\ Dr. Anju R. Ekka, \\ E-mail: dranju.ekka@gmail.com \\ Copyright: (C) the author(s), publisher and licensee Medip Academy. This is an open-access article distributed under \\ the terms of the Creative Commons Attribution Non-Commercial License, which permits unrestricted non-commercial \\ use, distribution, and reproduction in any medium, provided the original work is properly cited.
}

\begin{abstract}
Background: SDG 3 includes an ambitious target of reducing the global MMR to less than 70 per 100000 births by 2030. In order for effective initiation of measures to reduce maternal mortality it is necessary to assess the levels of delays, causes of death, health seeking behavior during antenatal and postnatal period and obstacles in reception of health services.

Methods: Retrospective study of 112 maternal death cases from a tertiary medical centre (Medical College) was done. The details of all the maternal mortalities from January 2018 to July 2020 were collected from the individual case sheets, facility-based maternal death review form and MDR Case Summary.

Results: The study reported a very high MMR of 802. Hypertensive disorders (36.61\%), Obstetric haemorrhage $(25.89 \%)$ and Sepsis $(14.29 \%)$ constituted the major direct cause of maternal deaths whereas anaemia was the most common indirect cause (7.14\%). First, second and third delays were present in $95.54 \%, 70.54 \%$ and $47.32 \%$ cases respectively.

Conclusions: Suboptimal ANC, long distances to reach final hospitals, high number of referrals and admission during complicated stage explains the very high maternal mortality in the present study. Application of Three Delay Model revealed that most of the maternal death occurred due to delays in multiple levels and first delay was the most commonly identified delay. Accelerated efforts should be implemented to minimize all the delays in order to achieve SDG goals.
\end{abstract}

Keywords: ICD Classification of maternal mortality, Maternal mortality ratio, Maternal mortality review, Three delay

\section{INTRODUCTION}

As per World Health Organization, "Maternal death is the death of a woman while pregnant or within 42 days of termination of pregnancy, irrespective of the duration and site of the pregnancy, from any cause related to or aggravated by the pregnancy or its management but not from accidental or incidental causes". ${ }^{1}$ Most maternal deaths are preventable, as the health-care solutions to prevent or manage complications are well known.
Maternal mortality is a critical indicator to assess the quality of services provided by a health care system. The standard indicator for measuring it is the Maternal Mortality Ratio (MMR), defined as the ratio of the number of maternal deaths per 100,000 live births. ${ }^{2}$ Global MMR of 211, in 2017 had declined $38 \%$ since 2000, when it was estimated at 342 maternal deaths per 100000 live births. ${ }^{1}$ SDG 3 includes an ambitious target of reducing the global MMR to less than 70 per 100000 births by 2030 with no country having a maternal 
mortality greater than 140 , a number twice the global average". ${ }^{1}$

It is heartening that the Maternal Mortality Ratio of India has declined to 113 in 2016-18 from 122 in 2015-17 and 130 in $2014-2016 .^{3}$ There is a need to further accelerate this decline for achieving our national and international targets and goals. The Maternal death review (MDR) process initiated by Government of India in 2010 is a tool available with health managers and policy makers at various levels to critically look at health system performance, identify gaps and initiate corrective step. ${ }^{2}$ The "three delay model" proposed by Thaddeus and Maine (1990) has demonstrated as a valuable and broadly acknowledged system for critical analysis of hindrances in obstetrics care and their contribution in maternal mortality. ${ }^{4}$

In order for effective initiation of measures to reduce maternal mortality it is necessary to assess the levels of delays, causes of death, health seeking behavior during antenatal and postnatal period and obstacles in reception of health services.

With this background the present study was done in the department of Obstetrics and Gynecology, Chhattisgarh Institute of Medical Sciences, Bilaspur, Chhattisgarh to determine the maternal mortality ratio, study the demographic characteristics, determine the causes of maternal death, assess the level of delays and to suggest recommendations for improving the quality of Obstetric care for reduction of maternal mortality.

\section{METHODS}

The present study was a retrospective study carried out in the Department of Obstetrics and Gyanecology at Chhattisgarh Institute of Medical Sciences which is a Government medical college and second biggest tertiary care centre of Chhattisgarh. It has an annual delivery rate of around 5500 and gets a large number of referrals from PHCs, CHCs, as well as district hospitals. It is a low resource setting having one blood bank and one emergency operation theatre with round the clock provision of emergency obstetric services to the patients.

The maternal deaths which met the WHO Criteria for Maternal Death ${ }^{1}$ were included in this study and deaths due to accidental or incidental causes were excluded. The details of all the maternal deaths from January 2018 to July 2020 were collected from the individual case sheets, Facility-Based Maternal Death Review Form and MDR Case Summary. ${ }^{2}$ The WHO Application of ICD-10 to deaths during pregnancy, childbirth and the puerperium: ICD-MM was used for classification of causes of maternal mortality. ${ }^{5}$ Three delays accounted were -

Type 1 delay - delayed recognition of a pregnancy complication and decision to go to a facility.
Type 2 delay - delays in reaching an emergency obstetric care facility.

Type 3 delay - lack of receipt of timely, adequate, and appropriate obstetric care at a health care facility.

A total of 112 maternal mortality cases were analyzed in this study for age, parity, education, residence, ANC care, referral characteristics, duration of hospital stay, interventions, causes of death and delays contributing to death. All the data was presented as frequencies and percentages.

\section{RESULTS}

In the study period, from January 2018 to July 2020, 112 maternal deaths were analyzed. There were 13,963 live births during this period. The maternal mortality ratio in the present study is 802 per 1,00,000 live births. The demographic characteristics are shown in Table 1.

Majority of the women $(37.5 \%)$ were young and belonged to 20-24 years of age, resided in rural areas $(91.07 \%)$ and had low socioeconomic status $(91.96 \%)$.

Table 1: Demographic characteristics $(\mathrm{N}=112)$.

\begin{tabular}{|lll|}
\hline \multicolumn{2}{|l|}{ Cases (n) } & Percentage \\
\hline Age at death (Years) & & \\
\hline$<20$ & 4 & 3.57 \\
\hline $20-24$ & 42 & 37.5 \\
\hline $25-29$ & 30 & 26.79 \\
\hline $30-34$ & 20 & 17.86 \\
\hline$>35$ & 16 & 14.29 \\
\hline Place of residence & & \\
\hline Rural & 102 & 91.07 \\
\hline Urban & 10 & 8.93 \\
\hline Education & & \\
\hline Illiterate & 37 & 33.04 \\
\hline Up to 5th & 40 & 35.71 \\
\hline 6th - 12th & 28 & 25 \\
\hline Beyond 12th class & 7 & 6.25 \\
\hline Socio economic status & & \\
\hline Lower class & 103 & 91.96 \\
\hline Middle class & 9 & 8.04 \\
\hline Booking status & & \\
\hline Unbooked & 23 & 20.54 \\
\hline Booked & 41 & 36.61 \\
\hline Registered & 48 & 42.86 \\
\hline
\end{tabular}

The ANC care and parity at death is represented in Table 2. Most of the cases $(38.39 \%)$ had received antenatal care by ANM. Half of the maternal deaths was observed in primipara $(50 \%)$ and the other half comprised of multipara and grand multipara in $35.71 \%$ and $14.29 \%$ cases respectively. 
The referral characteristics are shown in Table 3. The present study reported a high referral rate $(80.36 \%)$ and most of the cases $(68.75 \%)$ travelled more than 25 kilometers to reach the final hospital. In the present study majority of the maternal deaths $(53.57 \%)$ occurred within 24 hours of admission and $61.61 \%$ cases required ICU admission (Table 4).

Table 2: ANC care and parity $(\mathrm{N}=112)$.

\begin{tabular}{|lll|}
\hline \multicolumn{2}{l}{ Cases (n) } & Percentage \\
\hline No ANC & & \\
\hline ANM & 23 & 20.54 \\
\hline Rural Medical Assistant (RMA) & 20 & 17.86 \\
\hline MBBS & 43 & 14.39 \\
\hline Specialist & 16 & 8.93 \\
\hline Parity at death & 10 & \\
\hline Primipara & & 50 \\
\hline Multipara & 56 & 35.71 \\
\hline Grand multipara & 40 & 14.29 \\
\hline
\end{tabular}

Table 3: Referral characteristics $(\mathrm{N}=112)$.

\begin{tabular}{|lcc|}
\hline \multicolumn{2}{|l|}{ Cases (n) } & Percentage \\
\hline PHC & \multicolumn{2}{|c|}{} \\
\hline CHC & 43 & 9.82 \\
\hline District Hospital & 30 & 38.39 \\
\hline Private Hospital & 8 & 26.79 \\
\hline Walk in & 20 & 7.14 \\
\hline Distance travelled to & reach final hospital (Km) \\
\hline$<5$ & 11 & 9.82 \\
\hline $5-25$ & 24 & 21.43 \\
\hline $25-50$ & 36 & 32.14 \\
\hline$>50$ & 41 & 36.61 \\
\hline
\end{tabular}

Causes of death is represented in Table 5. Direct causes of maternal deaths were observed in $83.04 \%$ cases whereas indirect causes were present in remaining $16.96 \%$ cases. Hypertensive disorders $(36.61 \%)$, obstetric haemorrhage $(25.89 \%)$ and sepsis $(14.29 \%)$ constituted the major direct cause of maternal deaths whereas anaemia was the most common indirect cause $(7.14 \%)$ and a major contributory cause $(57.14 \%)$ of maternal deaths. All the delays were observed to be in higher proportion and type 1 delay $(95.54 \%)$ was the most common delay identified (Table 6).

Considering the timing of admission, a large number of cases $(81.25 \%)$ were admitted in third trimester and $61.61 \%$ cases were admitted in the intrapartum period. Most of the cases presented at late stage with serious complications $(66.07 \%)$. Regarding the timing of death, most of the maternal deaths $(77.69 \%)$ occurred in the post-partum period.
Table 4: Duration of hospital stay and interventions $(\mathrm{N}=112)$

\begin{tabular}{|c|c|c|}
\hline & Cases (n) & Percentage \\
\hline \multicolumn{3}{|c|}{ Duration of hospital stay (days) } \\
\hline$<1$ & 60 & 53.57 \\
\hline $1-7$ & 33 & 29.46 \\
\hline $8-14$ & 15 & 13.39 \\
\hline $15-42$ & 4 & 3.57 \\
\hline \multicolumn{3}{|l|}{ Interventions } \\
\hline Dilation \& curettage & 2 & 1.79 \\
\hline Vaginal delivery & 35 & 31.25 \\
\hline LSCS & 43 & 38.39 \\
\hline Hysterotomy & 3 & 2.68 \\
\hline Laparotomy & 6 & 5.36 \\
\hline Hysterectomy & 3 & 2.68 \\
\hline CG Balloon & 2 & 1.79 \\
\hline Manual removal of placenta & 2 & 1.79 \\
\hline Genital injury repair & 5 & 4.46 \\
\hline Bladder repair & 2 & 1.79 \\
\hline Dialysis & 2 & 1.79 \\
\hline ICU Admission & 69 & 61.61 \\
\hline Mechanical ventilation & 61 & 54.46 \\
\hline Cardiotonic support & 25 & 22.32 \\
\hline $\begin{array}{l}\text { Blood transfusion more than } 3 \\
\text { units }\end{array}$ & 30 & 26.79 \\
\hline
\end{tabular}

\section{DISCUSSION}

In the present study, analysis of 112 cases was done from January 2018 to July 2020 for determining the demographic characteristics, causes of deaths and delays leading to the maternal death. The maternal mortality ratio in the present study is 802 per 1,00,000 live births which is far higher than the national average (113) and also the state of Chhattisgarh (159). ${ }^{3}$ The MMR in this study is comparable to the results of Sundari et al (802) but very high in comparison to the other previous studies. $^{6-9}$

The high maternal mortality ratio in the present study can be explained by the fact that our centre is a tertiary referral centre attending large number of referred complicated cases and most of the patients are referrals from distant places. Most of the cases presented at late stage with serious complications $(66.07 \%)$ and expired within 24 hours of admission (53.57\%). Earlier studies have also reported similar reasons for increased maternal deaths. ${ }^{9,10}$

Majority of the death (37.5\%) was observed in 20-24 years of age which is consistent with earlier studies and the national data. ${ }^{3,6,8,10}$ Present study reported an equal proportion of maternal deaths in primipara and multipara. This result is varying from prior studies by Mittal et al and Soni et al where more maternal deaths were observed in multipara. ${ }^{9,10}$ This study reflects that pregnancy of any order can develop complications leading to mortality. 
Table 5: Causes of maternal deaths according to WHO ICD -10 (N=112).

\begin{tabular}{|c|c|c|c|c|}
\hline Type & Group name/numbers & Cause of death & Cases (n) & Percentage \\
\hline $\begin{array}{l}\text { Maternal death: } \\
\text { Direct }\end{array}$ & $\begin{array}{l}\text { 1) Pregnancy with abortive } \\
\text { outcome }\end{array}$ & Abortion & 2 & 1.79 \\
\hline \multirow{2}{*}{$\begin{array}{l}\text { Maternal death: } \\
\text { Direct }\end{array}$} & \multirow{2}{*}{$\begin{array}{l}\text { 2) Hypertensive disorders in } \\
\text { pregnancy, childbirth and } \\
\text { puerperium }\end{array}$} & Severe preeclampsia & 24 & 21.43 \\
\hline & & Eclampsia & 17 & 15.18 \\
\hline \multirow{4}{*}{$\begin{array}{l}\text { Maternal death: } \\
\text { Direct }\end{array}$} & \multirow{4}{*}{ 3) Obstetric haemorrhage } & PPH & 16 & 14.29 \\
\hline & & Ruptured uterus & 8 & 7.14 \\
\hline & & Placenta previa & 3 & 2.68 \\
\hline & & Abruptio placenta & 2 & 1.79 \\
\hline $\begin{array}{l}\text { Maternal death: } \\
\text { Direct }\end{array}$ & 4) Pregnancy related infection & Puerperal sepsis & 16 & 14.29 \\
\hline $\begin{array}{l}\text { Maternal death: } \\
\text { Direct }\end{array}$ & 5) Other obstetric complications & Amniotic fluid embolism & 2 & 1.79 \\
\hline $\begin{array}{l}\text { Maternal death: } \\
\text { Direct }\end{array}$ & $\begin{array}{l}\text { 6) Unanticipated complications of } \\
\text { management }\end{array}$ & $\begin{array}{l}\text { Aspiration } \\
\text { pneumonitis }\end{array}$ & 2 & 1.79 \\
\hline \multirow[t]{6}{*}{$\begin{array}{l}\text { Maternal death: } \\
\text { Indirect }\end{array}$} & 7) Non obstetric complications & Anaemia & 8 & 7.14 \\
\hline & & $\begin{array}{l}\text { Cardiac disorders } \\
\text { (MI/ RHD) }\end{array}$ & 2 & 1.79 \\
\hline & & Liver disorders (Jaundice) & 2 & 1.79 \\
\hline & & $\begin{array}{l}\text { Respiratory disorders } \\
\text { (Pulmonary embolism/ ARDS) }\end{array}$ & 5 & 4.46 \\
\hline & & $\begin{array}{l}\text { Neurological disorders } \\
\text { (CVA / Meningitis) }\end{array}$ & 2 & 1.79 \\
\hline & & $\begin{array}{l}\text { Infection } \\
\text { (Typhoid) }\end{array}$ & 1 & 0.89 \\
\hline
\end{tabular}

Table 6: Types of delays ( $\mathrm{N}=112)$.

\begin{tabular}{|lll|}
\hline Type of Delay & Cases $(\mathbf{n})$ & Percentage \\
\hline I & 107 & 95.54 \\
\hline II & 79 & 70.54 \\
\hline III & 53 & 47.32 \\
\hline
\end{tabular}

According to NFHS, In India and Chhattisgarh the proportion of women receiving antenatal care at least once during pregnancy was about $82.7 \%$ and $95.7 \%$ respectively for the period 2015-2016, but for the recommended minimum of four or more visits the corresponding figure drops to around $51.2 \%$ and $59.1 \%$ respectively. ${ }^{11}$ The present study observed suboptimal antenatal care compared to the national and state average as $79.46 \%$ cases had only one ANC visit which further decreased to $36.61 \%$ when WHO recommended four visits were considered. ANM was the major ANC service provider $(38.39 \%)$ in the present study whereas specialist care was received by only $8.93 \%$ women. These figures suggest that much more work needs to be done to address ANC utilization and quality obstetric care.

In the present study $61.61 \%$ cases were directly admitted in intrapartum period therefore, an opportunity for preventing maternal deaths was missed due to delay in admission of high-risk cases. Patel et al have also observed that period around birth is critical in saving lives of mother and more adverse birth outcome is reported in women referred during labour and delivery. ${ }^{12}$ Post-natal period is most crucial as most of the maternal deaths occur in this period as a consequence of poor antenatal care, delayed diagnosis and poor management of pregnancy complications. ${ }^{13}$ Present study reported maximum maternal mortality $(77.69 \%)$ in the postpartum period which is higher in comparison to study by Khandale et al (53.84\%). ${ }^{7}$

Direct causes of maternal mortality were present in $83.04 \%$ cases whereas indirect causes were responsible for $16.96 \%$ cases of maternal mortality. In this study, hypertension $(36.61 \%)$ was the major direct cause of maternal death which is consistent with the earlier studies. ${ }^{7-9}$ A WHO systemic analysis on global cause of maternal deaths revealed haemorrhage as the major cause of maternal mortality worldwide. $^{14}$ Obstetric haemorrhage is also the leading cause of maternal deaths in India. ${ }^{2}$ In our study haemorrhage $(25.89 \%)$ was the second major cause followed by sepsis (14.29\%). 
Anaemia was the most common indirect cause $(7.14 \%)$ and a major contributory cause $(57.14 \%)$ of maternal deaths which is comparable to the preceding studies. ${ }^{6,7,9}$

ICU admission (61.61\%) for cardiotonic and ventilatory support was the major intervention similar to the study by Khandale et al. ${ }^{7}$ Our centre being a tertiary referral centre and most of the cases having high-risk factors and complications requiring immediate delivery explain the high caesarean section rate of $38.39 \%$ in our study which is higher in comparison to the national average of $17 \% .^{11}$

Regarding the delays, first, second and third delays were present in $95.54 \%, 70.54 \%$ and $47.32 \%$ cases respectively. This study accounted a higher first level delay in comparison to earlier studies. ${ }^{7,9,15}$ In contrast to the present study, Khandale et al and Mittal et al have experienced a relatively low second delay $(10.25 \%$ and $34.06 \%$ respectively) and third delay $(3.84 \%$ and $1.64 \%$ respectively) and this difference could be explained by urban background, well equipped health facility, obstetric ICU, adequate health personnel and better referral linkage. ${ }^{7,9}$

First delay (decision to seek help) plays a significant role when maternal mortality is considered in India. ${ }^{15}$ The major causes attributable to high first delay in the present study are rural background, poverty and illiteracy. Lack of knowledge and awareness, underestimation of warning signs, customs and beliefs, lack of family support and absence of birth preparedness was noted as important factors for unacceptance of ANC services. Tragically in some cases patients were detected as high risks at early stages but they refused for referral and treatment at higher centres.

Current study also reported a high number of cases with second delay (reaching help). In this study, the average distance travelled to reach the final tertiary referral centre was 49.15 kilometers and majority of the cases $(68.75 \%)$ travelled a distance more than 25 kilometers before reaching our facility. Preceding studies by $\mathrm{Sk}$ et al and Hanson et al have also recorded that long distance to hospitals leads to delay in receiving adequate and appropriate care which contributes to high maternal mortality. ${ }^{15,16}$ Difficult terrain, bad roads, delay in arranging transport and poor vehicle conditions also significantly contributed to second delay.

In context of third delay (to receive adequate care), lack of communication between referral centres, delayed and multiple referrals was observed indicating unassured referral linkage. Lower health facilities had inadequate staff, resources, and also lack of knowledge and expertise for handling high risk obstetric cases. The present study observed a high referral rate $(80.36 \%)$. A high number of cases were referred from $\mathrm{CHC}(38.39 \%)$ and district hospital $(26.79 \%)$ and only $9.82 \%$ cases were referred from PHC. Earlier studies have also reported the similar trend of increased referrals. ${ }^{6,7}$ Lack of specialist/ trained providers (Anaesthetist and Gynaecologists), EmOC services, blood bank facility and ICU at First Referral Unit (FRU) was identified as a significant cause for increased referrals. In our centre, third delay was observed due to inadequate staff, lack of obstetric ICU and delay in arranging blood or blood components.

India has committed itself to the latest UN target for the Sustainable Development Goals (SDGs) by initiating various national programmes and schemes for improving maternal health. ${ }^{17}$ Despite the tremendous ongoing efforts to improve maternal health within India, there is a marked variation in socioeconomic factors and health care access across regions which describes the wide differences in MMR over the country. Very high maternal mortality ratio of our institute is quite alarming and must draw attention of policy makers for addressing the causative factors and developing strategies for prevention of maternal death. Measures should be targeted at minimizing each of the delays.

First delay needs to be addressed by use of preventive health care services and enhancing the awareness for danger signs in pregnancy and planning of birth preparedness. Antenatal services should be intensified, skilled birth attendance should be available within reach and high-risk cases should be referred to higher centre at earliest.

Women at high risk like preeclampsia, severe anaemia, previous caesarean, malpresentations etc. will benefit from direct admission to higher level facility for safe delivery. Maternal conditions that develop during labour, such as obstructed/ prolonged labour, antepartum and postpartum haemorrhage should have prompt detection and its effective management should be available at nearest higher health facility. Infection control practices and antibiotics should be meticulously used to prevent sepsis.

Strengthening of FRUs is an obligatory approach to ensure that they meet all requirements for sustained provision of CEmOC services within reach thus minimizing referrals to distant tertiary centres. Round the clock assured transport system should be available. All the tertiary centres should be equipped with adequate and skilled staff, sufficient blood components and obstetric ICU.

\section{CONCLUSION}

Hypertension, haemorrhage, sepsis and anaemia are preventable causes of maternal deaths. Suboptimal ANC, long distances to reach final hospitals, high number of referrals and admission during complicated stage explains the very high maternal mortality in the present study. Application of Three Delay Model revealed that most of the maternal death occurred due to delays in multiple levels and first delay was the most commonly identified delay. Accelerated efforts should be implemented to 
minimize all the delays. Skilled care before, during and after childbirth can save the lives of mothers. Improving access to adequate care, in particular for women who live far from health facilities, and encouraging women to seek appropriate and timely care are essential if the SDG goal is to be achieved.

Funding: No funding sources Conflict of interest: None declared

Ethical approval: The study was approved by the Institutional Ethics Committee

\section{REFERENCES}

1. Trends in maternal mortality: 2000 to 2017: estimates by WHO, UNICEF, UNFPA, World Bank Group and the United Nations Population Division. Geneva: World Health Organization; 2019.

2. Government of India. Guidelines for Maternal Death Surveillance and Response Available at: http://www.nhm.gov.in/images/pdf/programmes/mat ernal-health/guidelines/Guideline_for_MDSR.pdf. Accessed 18 April 2018.

3. Special bulletin on maternal mortality in India 201618-Census of India. Available at: https://censusindia.gov.in/. Accessed 10 January 2020.

4. Thaddeus S, Maine D. Too far to walk: maternal mortality in context. Soc Sci Med. 1994;38(8):109110.

5. World Health Organization. The WHO Application of ICD-10 to Deaths During Pregnancy, Childbirth and the Puerperium: ICD-MM. Geneva, Switzerland: World Health Organization, 2012. www.who.int/reproductivehealth/publications/monit oring/9789241548458/en/. Accessed 1 October 2019.

6. Sundari KP, Jayanthi RD, Ramasamy B. Trends in maternal mortality in a tertiary care hospital. Int $\mathbf{J}$ Reprod Contracept Obstet Gynecol. 2016;5:3659-62.

7. Khandale SN, Kedar K. Analysis of maternal mortality: a retrospective study at tertiary care centre. Int J Reprod Contracept Obstet Gynecol. 2017;6:1610-3.

8. Ghumare JP, Padvi NV. Assessment of maternal deaths using three delay model at a tertiary care centre in rural Maharashtra, India: retrospective six years study. Int J Reprod Contracept Obstet Gynecol. 2018;7:3043-7.
9. Mittal P, Kapoor G, Kumari N, Bajaj B. Review of Maternal Mortality at a Tertiary Care Hospital: What Have we Achieved? J Obst Gynecol India. 2019;69(2):149-54.

10. Soni M, Gupta PS, Gupta A. Causes of maternal mortality and changing trends: a retrospective analysis. Int J Sci Stud. 2016;4(7):105-107.

11. National family health survey (NFHS-4) 2015-16. International Institute for Population Sciences (IIPS) and ICF. 2017. Available at http://www.rchiips.org/nfhs or http://www.iipsindia.org. Accessed 10 January 2019.

12. Patel AB, Prakash AA, Raynes-Greenow C, Pusdekar YV, Hibberd PL. Description of interinstitutional referrals after admission for labor and delivery: a prospective population based cohort study in rural Maharashtra, India. BMC Health Serv Res. 2017; 17:360.

13. Singh S, Doyle P, Campbell OMR, Murthy GVS. Management and referral for high-risk conditions and complications during the antenatal period: Knowledge, practice and attitude survey of providers in rural public healthcare in two states of India. Reprod Health. 2019;16:100.

14. Say L, Chou D, Gemmill A, Tunçalp Ö, Moller AB, Daniels J, Gülmezoglu AM, et al. Global causes of maternal death: a WHO systematic analysis. Lancet Glob Health. 2014;2(6):e323-33.

15. Sk MIK, Paswan B, Anand A, Mondal NA. Praying until death: revisiting three delays model to contextualize the socio-cultural factors associated with maternal deaths in a region with high prevalence of eclampsia in India. BMC pregnancy and childbirth. 2019;19(1):314.

16. Hanson C, Cox J, Mbaruku G, Manzi F, Gabrysch S, Schellenberg D, et al. Maternal mortality and distance to facility-based obstetric care in rural southern Tanzania: a secondary analysis of crosssectional census data in 226000 households. Lancet Glob Health. 2015;3(7):e387-95.

17. Annual Report 2019-2020. Ministry of Health and Family Welfare-MoHFW, Government of India. Available at main.mohfw.gov.in. Accessed 28 September 2020.

Cite this article as: Jogi SR, Ekka AR. Maternal mortality review by three delay model: a retrospective study from a tertiary care hospital of Chhattisgarh. Int J Reprod Contracept Obstet Gynecol 2021;10:262-7. 